\title{
Prediction and Identification of Covariates of Intra-cerebral Hemorrhage
}

\author{
Afaq Ahmed Siddiqui ${ }^{1, *}$, Domenic V. Cicchetti ${ }^{2}$, M.Wasay ${ }^{3}$, Rafeeq Alam Khan ${ }^{4}$, \\ M. Ayub Khan Yousuf Zai ${ }^{5}$, Mansoor Ahmed ${ }^{1}$ and Shagufta Tabassum ${ }^{6}$ \\ ${ }^{1}$ Department of Pharm. Chem., Faculty of Pharmacy, University of Karachi, Pakistan \\ ${ }^{2}$ Child Study Center \& Departments of Biometry and Psychiatry, Yale University, USA \\ ${ }^{3}$ Neurology Section, Department of Medicine, The Aga Khan University, Karachi, Pakistan \\ ${ }^{4}$ Department of Pharmacology, Faculty of Pharmacy, University of Karachi, Pakistan \\ ${ }^{5}$ Department of Applied Physics, University of Karachi, Pakistan \\ ${ }^{6}$ Pharma Professional Services, Karachi, Pakistan
}

\begin{abstract}
The authors investigate the effects of clinical covariates upon the outcome of Intra-cerebral Hemorrhage (ICH) patients by applying a discriminate model of logistic regression.

About 985 patients's data with $\mathrm{ICH}$ have been collected using the International classification of diseases; ninth revision codes are also included. Diagnostic codes ( 434 for stroke and 431 for $\mathrm{ICH}$ ) were used to identify patients and confirmed by neuro-imaging of the patients using CT scan and MRI.

A univariate analysis of 88 covariates was undertaken and 46 of them reached statistical significance at an acceptable level of $p \leq 0.05$. The multivariable analysis exhibited a significant negative relationship between ICH and hypertension. The improvement among $\mathrm{ICH}$ patients having hypertension was found to be 0.5 with the $p=0.001, A R R=0.5,95 \%$ C.I. $0.3-0.8$. The development among ICH patients using antihypertensive medicine was 1.3 with $p=0.021, A R R=1.3,95 \%$ C.I. $1.0-1.6$. Thus present study manifested that $\mathrm{ICH}$ has strong relationship with use of antihypertensive medicine. The rate of perfection in the patients physiological conditions using antihypertensive medicine at the time of discharge was 2.9 times acquiring $p<0.001, A R R=2.9,95 \%$ C.I. $2.7-3.2$ as compared to those who could not use antihypertensive medicine. The change in ARR from 1.3 to 2.9 times depict that the exercise of antihypertensive medicine and $\mathrm{ICH}$ outcome are positively associated. The fluctuations in ARR of hypertensive range of systolic blood pressure (SBP) also indicate that the blood pressure range and $\mathrm{ICH}$ outcome are negatively correlated. The neurological symptomoatology, indistinct speech and double vision are important factors of proposed models. Moreover, a clear decrease was found in mental status from normal to coma in most suitable model.
\end{abstract}

Surgery is an important part of recovery, and estimated that the improvement among the $\mathrm{ICH}$ patients, who were treated under surgical aspects, was 1.4 times with significant $p$-value in the best models. The complication of pneumonia during treatment of $\mathrm{ICH}$ subjects has highly significant showing negative correlation with the given outcome variable.

The current model has $89.3 \%$ area under the curve with sensitivity (82.6\%), specificity $(81.3 \%)$ and p-value $(0.308)$. This indicates that the constructed model bestows the well performance of the $\mathrm{ICH}$ outcome and the model is considered as excellent.

Keywords: Intracerebral Hemorrhage, clinical covariates, multivariable analysis, logistic regression, HosmerLemeshow test, discriminate model, sensitivity and specificity.

\section{INTRODUCTION}

Human since his arrival on the earth has continuously encountered different risk factors affecting almost every facet of his life. It is therefore mandatory to rightly estimate these factors to secure the resources of life. There are many ways to estimate these risk factors; however one most applicable way to handle these issues is to utilize the statistical tools. The one identified technique is the application of modeling on the given set of variables.

*Address correspondence to this author at the Department of Pharm. Chem., Faculty of Pharmacy, University of Karachi, Pakistan;

E-mail: siddiquiaaspak@yahoo.com, aasiddiqui@uok.edu.pk
In the present study, multiple clinical variables were collected from a group of patients suffering from $\mathrm{ICH}^{1}$. $\mathrm{ICH}$ is a clinical condition / disorder that have important association with many common health risk factors, such as hypertension, diabetes mellitus etc. A systematic statistical analysis is required to find out actual clinical variables that affect adversely on clinical outcome of $\mathrm{ICH}$.

During the literature search it was noted that many crucial risk factors such as hypertension, smoking, level of blood pressure etc., were involved in the

\footnotetext{
${ }^{1}$ Rupture of blood vessel which causes Intracerebral Hemorrhage.
} 
development of ICH (Qureshi et al., 2001 [12]; Fewel et al., 2003 [13]). These risk factors can be classified as most or relatively less important. There are several defined criteria present that identify various variables related to $\mathrm{ICH}$. Different statistical analyses were applied to find out important risk factors that have different optimistic and pessimistic aspects (Daverat et al., 1991 [6]; Willmot et al., 2004 [7]; Woo et al., 2004 [10]). It is mandatory for the statistical method to exactly grasp most important and practical clinical variables, so that clinical research could focus on the key clinical variables that positively affect the outcomes of the treatment.

The data of present study is mainly qualitative type; that includes categorical outcome and mixed covariates. In the past multiple methods were used to analyze this type of data that include logistics, probit and log-linear approaches. During the statistical analysis of present data $(\mathrm{ICH})$ categorical response variable was treated differently than the usual continuous response variables by using the logistic regression model.

The rate of occurrence of Intracerebral Hemorrhage (ICH) is $10-20$ in one million populations. It is noted that people aged more than 55 years to be at the maximum risk (Siddiqui et al., 2013 [8]; Wasay et al., 2010 [9]; Woo et al., 2004 [10]). Intracerebral Hemorrhage is a major issue in third world countries and also in the USA and UK. Regrettably it is estimated that mortality of $\mathrm{ICH}$ is expected to become double by the year 2050. The unidentified reason is increase in aging population as well as changing in racial demographics (Park et al., 1998 [11]; Qureshi et al., 2001 [12]; Fewel et al., 2003 [13]).

Stroke is the third leading cause of death and the first leading cause of disability (Fewel et al., 2003 [13]; Woo et al., 2004 [10]). Spontaneous Intracerebral Hemorrhage accounts the 10 to $15 \%$ of all strokes (Takahashi et al., 2006 [14]). Approximately 50\% of all deaths occur within the first 48 hours. The survival rate in Intracerebral Hemorrhage is only $38 \%$ in one year (Qureshi et al., 2001 [12]; Fewel et al., 2003 [13]; Nassisi, 2005 [15]).

\section{MATERIALS AND METHODS}

\section{Materials}

In this paper we have collected 985 patients data including both female and male with Intracerebral Hemorrhage $(\mathrm{ICH})$ from one of the largest hospital of
Karachi. Patients were identified through medical records at the hospital using the International classification of diseases, using ninth revision coding system. Diagnostic codes (434 for stroke and 431 for $\mathrm{ICH})$ were utilized to identify patients of different sex. The diagnosis of $\mathrm{ICH}$ was confirmed by neuro-imaging in these patients.

\section{Methods}

In order to analyze this disease we first assessed the univariate correlation between the outcome variable with single covariate using Chi- square test and logistic regression analysis. All variables included in the tests with $p$-value less than 0.25 on given analysis were then diagnosed. A stepwise procedure was used to choose the variable with a value of $p<0.25$ as the followed the specific criteria to obtain the best multivariable model. We have constructed various models securing possible combinations of parameters that were significant accordingly.

The association between the various causal variables connected with each other biologically was also found. These variables such as age, hypertension, antihypertensive, SBP, mass effect, surgery, received oxygen and pneumonia, having significant p-values, were included odd ratios that could be changed but were not strongly associated with each other because of $p$-value $>0.05$. After developing main effect model, a relationship was tried to seek out with the interactions that were biologically meaningful.

Hosmer-Lemeshow test statistics was used to evaluate the goodness of fit for logistic model. It is frequently used in risk prediction models; particularly during the assessment of human disease models. (Hosmer and Lemeshow, 1980 [16]; Lemeshow, 1982 [17]; Hosmer and Lemeshow, 1989 [18]; Cessie et al., 1991 [19]; Hosmer, 1997 [20]; Collett, 2003 [21]; Chuang et al., 2009 [22]).

The discrimination of the fitted model is determined by the measurement of the area under the receiver operating characteristic (ROC) curve and indicates the cutoff that can predict the best outcome. In current study sensitivity and specificity analyses are based on binary classification of actual outcome and predictive probabilities of the constructed models.

\section{ANALYSIS AND RESULT}

The results obtained from this analysis, manifests that $p$-value was found to be less than 0.25 as in the criteria of univariate model or otherwise thought to be 
biologically meaningful (Bendel and Afifi, 1977 [23]; Hosmer and Lemeshow, 1989 \& 2000 [18]; Sauerbrei, 1999 [24]; Caberlotto and Hurd, 2001 [25]) also were entered into multivariable aspects using forward stepwise logistic approach, likelihood ratio test for the model selection. We also could have two continuous variables which were considered for age and length of stay. Analyzing the associations of the two variables with outcome, it has been found that the age seems to be insignificant. However of its nature as biologically important included in model.

In this examination of the disease, the following processes of including, deleting, refitting with different combinations of important variables and their biological interactions were obtained using multiple logistic methodology. One of the best fitted multiple logistic models is as follows:

Table 1: Multiple Logistic Regression Estimates of Covariates of Fitted Model, Showing Relative Risk (RR) and Adjusted Relative Risk (ARR) with 95\% Confidence Interval and p-value for the Outcome Variable of ICH

\begin{tabular}{|c|c|c|c|c|}
\hline Independent Factors Include in the Model & Field Name & RR(95\% C.I.) & ARR(95\% C.I.) & p-value \\
\hline AGE & AGE & $1.0(0.99 .1 .0)$ & $1.0(0.99,1.0)$ & 0.06 \\
\hline Hypertension & htn & $1.12(0.95,1.27)$ & $0.5(0.3,0.8)$ & 0.001 \\
\hline Coagulopathy & coag & $0.5(0.3,0.8)$ & $0.5(0.2,0.9)$ & 0.022 \\
\hline Antihypertansive & mahtn & $1.3(1.1,1.4)$ & $1.3(1.0,1.6)$ & 0.021 \\
\hline Slurred Speech & slusp & $1.2(1,1.3)$ & $0.7(0.5,1.0)$ & 0.023 \\
\hline Double Vision & dbvis & $0.95(0.6,1.3)$ & $0.4(0.2,1.0)$ & 0.04 \\
\hline Mental Status(Normal) & & & & 0.001 \\
\hline Sleepy & mssl1 & $0.9(0.7,1.0)$ & $1.0(0.9,1.1)$ & \\
\hline Confused & msco2 & $0.9(0.7,1.0)$ & $0.8(0.5,1.0)$ & \\
\hline Poorly Responsive & mspr3 & $0.7(0.3,0.8)$ & $1.0(0.7,1.1)$ & \\
\hline Unresponsive & msur4 & $0.5(0.3,0.7)$ & $0.7(0.5,0.9)$ & \\
\hline Coma & msco5 & $0.3(0.1,0.3)$ & $0.7(0.3,0.9)$ & \\
\hline Normal(90-140) & & & & 0.004 \\
\hline Mild.hypo. $(<90)$ & Isbp1 & $0.2(0.2,0.4)$ & $0.6(0.4,0.9)$ & \\
\hline Mild.htn.(141-160) & Isbp2 & $1(0.9,1.1)$ & $1.0(0.8,1.2)$ & \\
\hline Mod.htn.(161-200) & Isbp3 & $0.7(0.4,0.9)$ & $0.7(0.4,1.0)$ & \\
\hline Sev.htn. $(>200)$ & Isbp4 & $0.6(0.2,1.0)$ & $0.6(0.2,1.3)$ & \\
\hline Normal(Motor) & mtnor & $1.2(1.05,1.34)$ & $1.1(0.8,1.4)$ & 0.417 \\
\hline Rt.monoparesis & mtrmp & $1.6(0.9,1.7)$ & $1.6(0.8,1.7)$ & 0.064 \\
\hline Rt.basal Ganglia & lorbg & $0.96(0.85,1.1)$ & $1.0(0.7,1.1)$ & 0.56 \\
\hline Putamen & loput & $1.08(0.9,1.2)$ & $1.3(1.0,1.5)$ & 0.048 \\
\hline Pons & Iopon & $0.85(0.6,1.1)$ & $0.9(0.5,1.3)$ & 0.679 \\
\hline Cerebellum & locer & $1.4(1.1,1.6)$ & $1.5(1.1,1.7)$ & 0.014 \\
\hline Frontal Lobe & lofrl & $0.9(0.7,1.1)$ & $1.2(0.8,1.5)$ & 0.384 \\
\hline Parietal Lobe & lopal & $1.04(0.9,1.2)$ & $1.1(0.8,1.3)$ & 0.324 \\
\hline Midline Shift & memidsh & $0.6(0.4,0.6)$ & $0.9(0.5,1.2)$ & 0.421 \\
\hline Intraventricular Blood & meintb & $0.7(0.5,0.8)$ & $1.2(0.9,1.4)$ & 0.183 \\
\hline Hydrocephalus & mehydr & $0.5(0.4,0.7)$ & $0.9(0.5,1.2)$ & 0.402 \\
\hline Normal & menorm & $0.6(0.5,0.7)$ & $0.7(0.5,1.0)$ & 0.023 \\
\hline White Blood Cells $4 \times 10^{3}$ to $10^{4} / \mathrm{cc}$, normal) & & & & 0.11 \\
\hline$<4 \times 10^{3} / \mathrm{cc}$, leukopenia) & wbclp1 & $0.6(0.3,1.0)$ & $0.4(0.2,1.0)$ & \\
\hline$>10^{4} / \mathrm{cc}$, leukocytosis) & wbclc2 & $0.8(0.7,0.9)$ & $1.0(0.9,1.2)$ & \\
\hline IVABX & reivab & $0.7(0.5,0.8)$ & $0.9(0.6,1.2)$ & 0.561 \\
\hline Oxygen & reoxyg & $0.5(0.4,0.6)$ & $0.9(0.5,1.1)$ & 0.296 \\
\hline Surgery & surger & $1.2(0.9,1.3)$ & $1.4(1.1,1.6)$ & 0.015 \\
\hline Pneumonia & & & & 0.001 \\
\hline Present & pnem1 & $0.5(0.3,0.6)$ & $0.6(0.3,0.8)$ & \\
\hline Don't know & pnem2 & $0.8(0.7,0.9)$ & $0.8(0.6,1.0)$ & \\
\hline Antihypertansive & dmant & $2.9(2.7,3.0)$ & $2.9(2.7,3.2)$ & $<0.001$ \\
\hline ASA & dmasa & $1.5(1.2,1.6)$ & $1.3(0.8,1.6)$ & 0.127 \\
\hline
\end{tabular}


$\mathrm{g}(\mathrm{x}): \quad 1.6-0.01$ (age)-1.1(htn) -1.3 (coag) +0.6 (mahtn)0.6 (slusp) -1.8 (dbvis) +0.12 (mssl1)- 0.65 (msco2) 0.1 (mspr3) -0.96 (msur4) -1.12 (msco5) -1.1 (lsbp1) + 0.05 (Isbp2)-0.98(Isbp3)-1.19(Isbp4)+ 0.2 (mtnor) + 2.04 (mtrmp) $\quad-0.15$ (lorbg) +0.67 (loput)- 0.23 (lopon) +1.4 (locer) +0.42 (lofrl) +0.3 (lopal) -0.3 (memidsh $)+$ 0.5 (meintb)- 0.33(mehydr)- 1.0(menorm)-1.5(wbclp1) + 0.1 (wbclc2)-0.2(reivab)-0.4(reoxyg)+ 1.1 (surger)1.3(pnem1) - 0.6(pnem2) +2.5(dmant) + 0.8(dmasa)

The parametric inequality of the model was determined by measuring the accuracy, sensitivity, specificity and area under the receiver operating characteristic (ROC) curve (Table 2).

Table 2: Sensitivity and Specificity Analysis with $95 \%$ C.I. of Best Fitted Multiple Logistic Regression Model

\begin{tabular}{|c|c|}
\hline Cutoff Value & $\mathbf{0 . 5 6 6}$ \\
\hline \hline Area under ROC curves (95\% C.I.) & $0.893(0.870,0.916)$ \\
\hline Sensitivity (95\% C.I.) & $0.826(0.787,0.859)$ \\
\hline Specificity (95\% C.I) & $0.813(0.766,0.852)$ \\
\hline Positive Predictive Value (95\% C.I.) & $0.856(0.819,0.887)$ \\
\hline Negative Predictive Value (95\% C.I.) & $0.776(0.728,0.817)$ \\
\hline
\end{tabular}

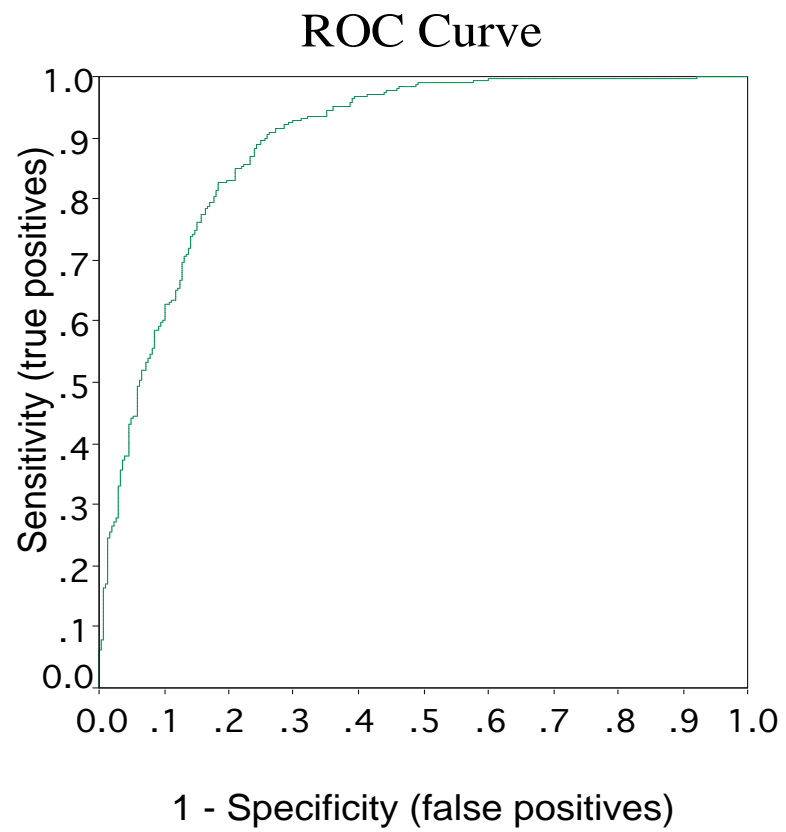

\section{DISCUSSION}

It has been revealed that the univariate approach inferred the observations with their results as in fact narrated that out of 88 covariates 46 were found to be significant according to $p$-value $<0.05$.
Over all analyses illustrate that $84.8 \%$ subjects were found to have hypertension as major risk factor explained by computations. This includes that hypertensive subjects 1.12 times as compared to non hypertensive patients indicating (95\% C.I.: $0.95-1.27)$ for outcome. On the contrary to this the multivariable technique using multiple logistic regressions exhibited a significant negative relationship between $\mathrm{ICH}$ and hypertension. The upgrading among $\mathrm{ICH}$ patients having hypertension was 0.5 securing $p=0.001$, $\mathrm{ARR}=0.5,95 \%$ C.I. $0.3-0.8$ as compared to non hypertensive's model parameters.

The present investigations as reported in this paper under the heading of multivariable analysis were in accordance to the results of a previous work carried out by Ariesen et al. 2003 [26]. Other studies were carried out by Brott et al., 1986 [27]; Juvela et al., 1995 [28]; Dandapani et al., 1995 [29]; Thrift et al., 1998 [30]; Broderick et al., 1999 [31]; Woo et al., 2004 [10]; Kim et al., 2005 [32]; Sturgeon et al., 2007 [33] and Chuang et al., 2009 [22] manifested a clear relationship between hypertension and $\mathrm{ICH}$. The results of present study strictly judge the scientific evaluation of direct relation of hypertension with $\mathrm{ICH}$.

In this paper data sets showed that $65.6 \%$ subjects were using antihypertensive medicine. The current approach of this analysis exhibited a significant relationship between $\mathrm{ICH}$ and antihypertensive medicine conditionally if these data sets were utilized for other model parameters (Table 1). The up-gradation of the parametric values in the $\mathrm{ICH}$ patients using antihypertensive medicine was $1.3(p=0.021$, $\mathrm{ARR}=1.3,95 \%$ C.I. $1.0-1.6$ ) as compared to those unavailability of antihypertensive medicine. It has been reported by Thrift et al. (1998) [30], that the use of antihypertensive medicine decreased the risk of $\mathrm{ICH}$ due to hypertension. Thus results of our study displayed that $\mathrm{ICH}$ has strong relationship with use of antihypertensive medicine and it can be hypothesized that the use of antihypertensive medicine reduces the risk factor of possible occurrence of $\mathrm{ICH}$ due to hypertension. Our overall result of this investigation obviously presented that $84.8 \% \mathrm{ICH}$ patients have a risk factor of hypertension, $65.6 \% \mathrm{ICH}$ patients take antihypertensive medicine while $31.9 \%$ do not take any medicine. So it has been concluded that improvement in $\mathrm{ICH}$ patients, the enhanced hypertension was recorded 0.5 times $(\mathrm{ARR}=0.5)$ as compared to undeveloped hypertension. Moreover, the time of discharge, $56 \%$ subjects were found using antihypertensive medicine. Multivariable approach illustrated relationship between $\mathrm{ICH}$ and 
antihypertensive medicine. The improvement among $\mathrm{ICH}$ patients using antihypertensive medicine at the time of discharge as consequence from multiple logistic model was evaluated 2.9 times $(p<0.001, A R R=2.9$, $95 \%$ C.I. $2.7-3.2)$. Thus the modulation in adjusted relative risk (ARR) as recorded from 1.3 to 2.9 times in antihypertensive medicine that depicts that the use of antihypertensive medicine and $\mathrm{ICH}$ outcome variable that are positively correlated.

As it has been observed that hypertension is a significant risk factor, the different group of level or range of blood pressure plays an important role in developing the subjects. It is important to inform that there are four groups of range of blood pressure in the present study. Two, at the time of admission after $\mathrm{ICH}$, i.e., initial SBP and DBP and two, during the period of admission in hospital, i.e., lowest SBP and DBP.

The present data sets are analyzed for different range of blood pressure and it was pointed out that, in initial systolic blood pressure a large number of patients $(78 \%)$ belongs to the hypertensive blood pressure group of range $(141-200 \mathrm{~mm} \mathrm{Hg})$ and $21 \%$ patients have normal blood pressure group of range (90-140 mm Hg). Similarly in initial diastolic blood pressure group, $56 \%$ belong to the hypertensive blood pressure group of range $(>90 \mathrm{~mm} \mathrm{Hg})$ and $40.9 \%$ patients have normal diastolic blood pressure group of range $(60-90 \mathrm{~mm} \mathrm{Hg})$. In the same way during the hospitalization of patients with SBP it was found that 25 $\%$ belong to the hypertensive blood pressure group of range $(141-200 \mathrm{~mm} \mathrm{Hg})$ and $64 \%$ patients have normal blood pressure group of range $(90-140 \mathrm{~mm} \mathrm{Hg})$. Similarly with reference to diastolic blood pressure during the hospitalization, $10 \%$ of patients belong to the hypertensive blood pressure group of range $(>90$ $\mathrm{mm} \mathrm{Hg}$ ) and $62 \%$ patients have normal diastolic blood pressure group of range $(60-90 \mathrm{~mm} \mathrm{Hg})$.

The actual improvement among $\mathrm{ICH}$ patients belonging to hypertensive lowest systolic blood pressure group $(141-160 \mathrm{~mm} \mathrm{Hg})$ was 1.0 times $(p=$ 0.004$, ARR $=1.0,95 \%$ C.I. $0.8-1.2)$, for the range of $(161-200 \mathrm{~mm} \mathrm{Hg})$ was 0.7 times $(p=0.004$, ARR $=0.7$, $95 \%$ C.I. $0.4-1.0)$ and for the range of $(>200 \mathrm{~mm} \mathrm{Hg})$ was 0.6 times $(p=0.004, A R R=0.6,95 \%$ C.I. $0.2-1.3)$ as compared to the normal range $(90-140 \mathrm{~mm} \mathrm{Hg})$ of blood pressure as operated in other variables. Thus the change in adjusted relative risk (ARR) of hypertensive range of systolic blood pressure also indicates that the blood pressure range and $\mathrm{ICH}$ outcome variable are negatively associated.
Results of current data analysis as reported in multivariable case are in accordance to the results of previous studies. Leppala et al. (1999) [34] showed that the risk of $\mathrm{ICH}$ is increased with increasing systolic and diastolic blood pressure. Song et al. (2004) [35] supported the closer relationship between hemorrhagic stroke and blood pressure level. Kin et al. (2005) [32] indicated the risk ratio of blood pressure level and hemorrhage was associated. Hence it can be concluded that the risk of $\mathrm{ICH}$ is increased with increasing systolic blood pressure, as already hypothesized above in discussion of hypertension that $\mathrm{ICH}$ has strong relationship with hypertension.

The second and third highest frequencies of risk factor noted in this study were diabetes mellitus $(24.3 \%)$ and hyperlipidemia (13.4\%). As far as these two major risk factors are involved, results are quite interesting. Work done by researchers (Wong et al., 1999 [36]; Arboix et al., 2000 [37]; Ariesen et al., 2003 [26]; Passero et al., 2003 [38]; Rosand et al., 2004 [39]) illustrated that diabetes mellitus is not an independent risk factor for the development of $\mathrm{ICH}$. However it increases mortality rate in subjects with $\mathrm{ICH}$ since hyperglycemia and also is reported to enhance edema and infarct size and with reduction in cerebral blood flow and cerebrovascular reserves. These manifest an indirect correlation of DM and hyperlipidemia with $\mathrm{ICH}$. Sturgeon et al. 2007 [33] also showed that diabetes mellitus is not associated ( $p>0.05)$ with $\mathrm{ICH}$ either in univariate and multivariate models. Arboix et al. (2000) [37] depicted that diabetes mellitus increases the mortality rate in subjects with $\mathrm{ICH}$. The univariate and multivarible analysis of present data showed insignificant relationship between $\mathrm{ICH}$ and these risk factors. Diabetes mellitus and hyperlipidemia were not selected in the model as a candidate of best.

The expected assessment of coagulopathy that 3.7 $\%$ subjects to this risk factor The univariate analysis showed less clinical improvement $(0.5$ times $)$ in coagulopathy subjects with $\mathrm{ICH}$, as compared to non coagulopathic subjects (95\% C.I.: $0.3-0.8$ ) for outcome index. Multivariable analysis showed a negative significant relationship between $\mathrm{ICH}$ and coagulopathy when adjusted for other variables in the best fitted model. The improvement among $\mathrm{ICH}$ patients with coagulopathy was 0.5 times $(p=0.02, A R R=0.5,95 \%$ C.I. $0.2-0.9$ ) as compared to without coagulopathy when adjusted for other variables in the model.

Present Model has $89.3 \%$ area under the curve with sensitivity (82.6\%), specificity (81.3\%) and p-value 
(0.308). This indicates that the model give the impression to fit quite well for predictive performance of the ICH outcome variable. The value of the area under the curve, sensitivity and specificity showed that the model is applicable.

\section{CONCLUSION}

The present model construction approach of multiple logistic regression suggested that $\mathrm{ICH}$ has strong relationship with hypertension and the use of antihypertensive medicine was found to play a pivotal role in reduction of the risk of $\mathrm{ICH}$ due to hypertension. They exhibited a clear up gradation as mentioned earlier (1.3 times) in patients as compared to those not using antihypertensive medicine. Likewise, the current analyses on this context clear improvement (2.9 times) among $\mathrm{ICH}$ patients who were using antihypertensive medicine at the time of discharge. Thus the change in adjusted relative risk from 1.3 to 2.9 times illustrate that the use of antihypertensive medicine and $\mathrm{ICH}$ outcome variable are positively associated. Similarly, the change in adjusted relative risk of different range of level of blood pressure showed that the blood pressure level and $\mathrm{ICH}$ outcome are significantly associated. Therefore, it can be tested that the risk factor of $\mathrm{ICH}$ is increased with the blood pressure. From other risk factors, coagulopathy was found as a negatively significant risk factor for $\mathrm{ICH}$ outcome in the fitted model.

Multiple logistic method revealed that neurological symptomatology, slurred speech and double vision are important factors of proposed models. Moreover, multivariable analysis discovered a clear decrease in mental status from normal to coma in applicable model. Putamen and cerebellum were positively significant with $\mathrm{ICH}$ outcome.

Current statistical evaluation found that the surgery is an important part of recovery of $\mathrm{ICH}$ patients as estimated that the improvement among the $\mathrm{ICH}$ patients are recorded and treated with surgery, was 1.4 times with significant $p$-value in best multiple logistic models. Multivariable analysis displayed that the complication of pneumonia during treatment of $\mathrm{ICH}$ subjects has highly significant negative correlation.

The above results are intended that the multivariable analyses using logistic regression and statistical diagnostic tools are better techniques of binary response outcomes and provide an easy interpretation and identification of the most valuable factors from the multitude factor disease data.

\section{REFERENCES}

[1] Cleary PD, Angel R. The Analysis of Relationship Involving Dichotomous Dependent Variables. Journal of Health and Social Behavior 1984; 25(3): 334-348.

http://dx.doi.org/10.2307/2136429

[2] Boos DD. Analysis of Dose-Response Data in the Presence of Extrabinomial Variation. Applied Statistics 1993; 42(1): 173-183.

http://dx.doi.org/10.2307/2347419

[3] Thiex R, Rohde V, Rohde I, Mayfrank L, Zeki Z, Thron A Gilsbach OM, Uhl E. Frame-based and Frameless Stereotactic Hematoma Puncture and Subsequent Fibrinolytic Therapy for the Treatment of Spontaneous Intracerebral Hemorrhage. J Neurol 2004; 251: 1443-1450. http://dx.doi.org/10.1007/s00415-004-0554-5

[4] Khuri Al, Mukherjee B, Sinha BK, Ghosh M. Design Issues for Generalized Linear Models: A Review. Statistical Science 2006; 21(3): 376-399.

http://dx.doi.org/10.1214/088342306000000105

[5] Blackstone RP, Rivera LA. Predicting Stricture in Morbidly Obese Patients Undergoing Laparoscopic Roux-en-Y Gastric Bypass: A Logistic Regression Analysis. J Gastrointest Surg 2007.

http://dx.doi.org/10.1007/s11605-007-0135-x

[6] Daverat P, Castel JP, Dartigues JF, Orgogozo JM. Death and Functional Outcome after Spontaneous Intracerebral Hemorrhage a Prospective Study of 166 Cases using Multivariate Analysis. Stroke 1991; 22: 1-6. http://dx.doi.org/10.1161/01.STR.22.1.1

[7] Willmot M, Bee JL, Bath PMW. High Blood Pressure in Acute Stroke and Subsequent Outcome: A Systematic Review. Hypertension. Journal of the American Heart Association 2004; 43: 18-24.

[8] Siddiqui AA, Siddiqui JS, Wasay M, Azam SI, Ahmed A. A Dynamical Study of Risk Factors in Intracerebral Hemorrhage using Multivariate Approach. International Journal of Statistics in Medical Research 2013; 2(1): 23-33. http://dx.doi.org/10.6000/1929-6029.2013.02.01.03

[9] Wasay M, Khatri IA, Khealani B, Afaq M. Temporal Trends in Risk Factors and Outcome of Intracerebral Hemorrhage Over 18 Years at a Tertiary Care Hospital in Karachi, Pakistan. J of Stroke and Cerebrovascular Diseases 2010; 21(4): 289292.

http://dx.doi.org/10.1016/j.jstrokecerebrovasdis.2010.09.001

[10] Woo D, Haverbusch M, Sekar P, Kissela B, Khoury J, Schneider A, Kleindorfer D, Szaflarski J, Pancioli A, Jauch E, Moomaw C, Sauerbeck L, Gebel J, Broderick J. Effect of Untreated Hypertension on Hemorrhagic Stroke. Stroke 2004.

http://dx.doi.org/10.1161/01.STR.0000130855.70683.c8

[11] Park JK, Kim HJ, Chang SJ, Koh SB, Koh SY. Risk Factors for Hemorrhagic Stroke in Wonju, Korea. Yonsei Medical Journal 1998; 39(3): 229-235.

http://dx.doi.org/10.3349/ymj.1998.39.3.229

[12] Qureshi Al, Tuhrim S, Broderick JP, Batjer $\mathrm{HH}$, Hondo $\mathrm{H}$, Hanley DF. Spontaneous Intra cerebral Hemorrhage: Review Article. New Engl J Med 2001; 344(19): 1450-1459. http://dx.doi.org/10.1056/NEJM200105103441907

[13] Fewel MF, Thompson BG, Hoff JT. Spontameous Intra circular hemorrhage: a review. Neursurg Focus 2003; 15(4): 1-16.

[14] Takahashi O, Cook EF, Nakamura T, Saito J, Ikawa F, Fukui T. Risk Stratification for In-hospital Mortality in Spontaneous Intracerebral Haemorrhage: A Classification and Regression Tree Analysis. Q J Med 2006; 99: 743-750. http://dx.doi.org/10.1093/qjmed/hcl107

[15] Nassisi D. Stroke, Hemorrhagic 2005. 
[16] Hosmer DW, Lemeshow S. A Goodness-of-fit test for the Multiple Logistic Regression Model. Communication in Statistics 1980; 9(10): 1043-1069. http://dx.doi.org/10.1080/03610928008827941

[17] Lemeshow S, Hosmer DW. The use of Goodness of fit Statistics in the Development of Logistic Regression Model. American Journal of Epidemiology 1982; 115(1): 92-166.

[18] Hosmer DW, Lemeshow S. Applied Logistic Regencies. A Wiley-Interscience Publication 1989, 2000.

[19] Cessie LS, Houwelingen JCV. A Goodness-of-Fit Test for Binary Regression Models, Based on Smoothing Methods. Biometrics 1991; 47(4): 1267-1282. http://dx.doi.org/10.2307/2532385

[20] Hosmer DW, Hosmer T, Cessie SL, Lemeshow S. A Compairision of Goodness-of-fit tests for the Logistic Regression Model. Statistics in Medicine 1997; 16: 965-980. http://dx.doi.org/10.1002/(SICI)10970258(19970515)16:9<965::AID-SIM509>3.0.CO;2-O

[21] Collett D. Modeling Binary data, $2^{\text {nd }}$ edition. Chapman and Hall 2003.

[22] Chuang YC, Chen YM, Peng SK, Peng SY. Risk Stratification for Redacting 30-day mortality of Intracerebral Hemorrhage. International Journal for Quality in Health Care 2009; 21(6): 441-447. http://dx.doi.org/10.1093/intahc/mzp041

[23] Bendel RB, Afifi AA. Comparison of Stopping Roles in Forward "Stepwise" Regression. J of the American Statistical Association 1977; 72(357): 46-53.

[24] Sauerbrei W. The use of Resampling Methods to Simplify Regression Models in Medical Statistics. Appl Statist 1999; 48(3): 313-329. http://dx.doi.org/10.1111/1467-9876.00155

[25] Caberlotto L, Hurd YL. Neuropeptide Y Y1 and Y2 Receptor mRNA Expression in the Prefrontal Cortex of Psychiatric Subjects Relationship of Y2 Subtype to Suicidal Behavior. Neuropsychopharmacology 2001; 25: 91-97. http://dx.doi.org/10.1016/S0893-133X(00)00231-1

[26] Ariesen MJ, Claus SP, Rinkel GJE, Algra A. Risk Factors for Intracerebral Hemorrhage in the General Population: A Systematic Review. Stroke 2003; 34: 2060-2065. American Heart Association. http://dx.doi.org/10.1161/01.STR.0000080678.09344.8D

[27] Brott T, Thalinger K, Hertzberg V. Hypertension as a Risk Factor for Spontaneous Intracerebral Hemorrhage. Stroke 1986; 17(6): 1078-1083. American Heart Association. http://dx.doi.org/10.1161/01.STR.17.6.1078

[28] Juvela S, Hillbom M, Palomäki H. Risk Factors for Spontaneous Intracerebral Hemorrhage. Stroke 1995; 26: 1558-1564.

http://dx.doi.org/10.1161/01.STR.26.9.1558

[29] Dandapani BK, Suzuki S, Kelley RE, Iglesias YR, Duncan RC. Relation Between Blood Pressure and Outcome in Intracerebral Hemorrhage. Stroke 1995; 26: 21-24. American Heart Association.

http://dx.doi.org/10.1161/01.STR.26.1.21
[30] Thrift AG, McNeil JJ, Forbes A, Donnan GL. Three Important Subgroups of Hypertensive Persons at Greater Risk of Intracerebral Hemorrhage. Hypertension 1998; 31: 12231229. American Heart Association.

http://dx.doi.org/10.1161/01.HYP.31.6.1223

[31] Broderick JP, Adams HP, Barsan W, Feinberg W, Feldmann E, Grotta J, Kase C, Krieger D, Mayberg M, Tilley B, Zabramski JM, Zuccarello M. Guidelines for the Management of Spontaneous Intracerebral Hemorrhage: A Statement for Healthcare Professionals From a Special Writing Group of the Stroke Council, American Heart Association. Stroke 1999; 30: 905-915.

http://dx.doi.org/10.1161/01.STR.30.4.905

[32] Kim HC, Nam CM, Jee SH, Suh I. Comparison of Blood Pressure Associated Risk of Intracerebral Hemorrhage and Subarachnoid hemorrhage: Hypertension 2005; 46: 393-397. American Heart Association.

http://dx.doi.org/10.1161/01.HYP.0000177118.46049.e6

[33] Sturgeon JD, Folsom AR, Longstreth WT, Shahar E, Rosamond WD, Cushman M. Risk Factors for Intracerebral Hemorrhage in a Pooled Prospective Study. Stroke 2007; 38: 2718-2725.

http://dx.doi.org/10.1161/STROKEAHA.107.487090

[34] Leppälä JM, Virtamo J, Fogelholm R, Albanes D, Heinonen OP. Different Risk Factors for Different Stroke Subtypes: Association of Blood Pressure, Cholesterol, and Antioxidants. Stroke 1999; 30: 2535-2540. American Heart Association.

http://dx.doi.org/10.1161/01.STR.30.12.2535

[35] Song YM, Sung J, Lawlor DA, Smith GD, Shin Y, Ebrahim S. Blood Pressure, Haemorrhagic Stroke and Ischaemic Stroke: The Korean National Prospective Occupational Cohort Study. BMJ 2004; 328: 324-325.

http://dx.doi.org/10.1136/bmj.328.7435.324

[36] Wong KS. Risk Factors for Early Death in Acute Ischemic Stroke and Intracerebral Hemorrhage: A Prospective Hospital-Based Study in Asia. Stroke 1999; 30: 2326-2330. American Heart Association.

http://dx.doi.org/10.1161/01.STR.30.11.2326

[37] Arboix A, Massons J, García-Eroles L, Oliveres M, Targa C. Diabetes is an Independent Risk Factor for In-Hospital Mortality from Acute Spontaneous Intracerebral Hemorrhage. Diabetes Care 2000; 23: 1527-1532.

http://dx.doi.org/10.2337/diacare.23.10.1527

[38] Passero S, Ciacci G, Ulivelli M. The Influence of Diabetes and Hyperglyce-mia on Clinical Course after Intracerebral Hemorrhage. Stroke 2003.

[39] Rosand J, Eckman MH, Knudsen KA, Singer DE, Greenberg $S$. The Effect of Warfarin and Intensity of Anticoagulation on Outcome of Intrac-erebral Hemorrhage. Arch Intern Med 2004; 164: 880-884.

http://dx.doi.org/10.1001/archinte.164.8.880

Received on 15-11-2014
http://dx.doi.org/10.6000/1929-6029.2015.04.01.1

Accepted on 30-12-2014

Published on 27-01-2015

(c) 2015 Siddiqui et al.; Licensee Lifescience Global.

This is an open access article licensed under the terms of the Creative Commons Attribution Non-Commercial License (http://creativecommons.org/licenses/by-nc/3.0/) which permits unrestricted, non-commercial use, distribution and reproduction in any medium, provided the work is properly cited. 